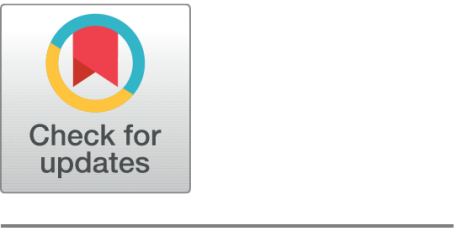

G OPEN ACCESS

Received: 19-04-2020

Accepted: 26-04-2020

Published: 28-05-2020

Editor: Dr. Natarajan Gajendran

Citation: Sahu D, Panda NR (2020) Synthesis of Cerium doped Zinc oxide nanoparticles by aqueous precipitation method and study on the structural and optical properties. Indian Journal of Science and Technology 13(14): 1480-1485. https ://doi.org/10.17485/JJST/v13i14.337

*Corresponding author. Dojalisa Sahu

School of Applied Sciences, Centurion University of Technology and Management, Odisha, India dojalisa.sahu@cutm.ac.in

Funding: None

Competing Interests: NOne

Copyright: @ 2020 Sahu, Panda. This is an open access article distributed under the terms of the Creative Commons Attribution License, which permits unrestricted use, distribution, and reproduction in any medium, provided the original author and source are credited.

Published By Indian Society for Education and Environment (iSee)

\section{Synthesis of Cerium doped Zinc oxide nanoparticles by aqueous precipitation method and study on the structural and optical properties}

\author{
Dojalisa Sahu ${ }^{1 *}$, Nihar R Panda ${ }^{2}$ \\ 1 School of Applied Sciences, Centurion University of Technology and Management, Odisha, \\ India \\ 2 School of Basic Sciences, Indian Institute of Technology Bhubaneswar, Odisha, , India
}

\begin{abstract}
Objectives: To understand the effect of impurity element doping; especially rare earth (Ce) ions on structural and optical properties of $\mathrm{ZnO}$. Method: Coprecipitation method is used to prepare nanoparticles of pristine $\mathrm{ZnO}$ and $\mathrm{ZnO}$ doped with cerium. This method is found to be very useful in preparing nanoparticles of very low size. The property of the samples is studied by different characterization techniques such as Powder X-ray diffraction (PXRD), field emission scanning electron microscopy (FESEM), UV-visible (UV-Vis) spectroscopy, photoluminescence $(\mathrm{PL})$ spectroscopy and Fourier transform infrared (FTIR) spectroscopy. Findings: XRD studies reveal the crystallographic data which tells that the prepared $\mathrm{ZnO}$ is of hexagonal wurtzite phase with size of $35 \mathrm{~nm}$. Crystallite size and unit cell volume increase with cerium doping. FESEM study shows the formation of nanoparticles. FTIR study shows the position of different stretching and bending modes present in the sample. It confirms the position of metal-oxygen bond. Photoluminescence and UV-VIS spectra show the interesting optical properties of Ce-ZnO. The PL spectra show the presence of UV excitonic emission and visible defect emissions along with emissions due to dopant. Upon Ce doping, ZnO shows a new peak around $645 \mathrm{~nm}$ ascribed to the transition related to dopant level. Enhancement in emission in visible-red region of $\mathrm{ZnO}$ with Ce doping will be useful in preparation of LED.
\end{abstract}

Keywords: ZnOCe; Optical study; Photoluminescence; Co-precipitation

\section{Introduction}

Nanotechnology is one of the interesting branches of modern science which has scope in many fields for designing of products for human use ${ }^{(1)}$. Nanomaterials are used in medicine, transport, food packaging, electronics and space technology showing better efficiency in comparison to conventional materials ${ }^{(1)}$. Zinc oxide is one such material which has tremendous applications in the above fields ${ }^{(2-4)}$. It has some novel physical 
and chemical properties which enhances its applicability. It is a wide band gap semiconducting material which finds its use in opto-electronics. The band gap of $\mathrm{ZnO}$ is $3.37 \mathrm{eV}$ with high excitonic binding energy $(60 \mathrm{meV})^{(2-4)}$. It has also high breakdown strength. Due to these properties, $\mathrm{ZnO}$ is largely used in electronic, photonic, sensing devices as well as for high-frequency applications. $\mathrm{ZnO}$ is also used in materials used for varistors, transparent conductors and transparent UV-protection films. The wide band gap of $\mathrm{ZnO}$ is responsible for its applicability as a potential material for fabricating light emitting diodes (LEDs), laser diodes (LDs) and detectors ${ }^{(2,4)}$.

Researchers have used many chemical methods for the preparation of nano $\mathrm{ZnO}$ in different size and shapes. Some of these methods are hydrothermal, sol-gel, co-precipitation, chemical vapour deposition, sputtering and pulsed laser deposition ${ }^{(4)}$. Chemical methods are very simple and cost effective for the preparation of nanomaterials. $\mathrm{ZnO}$ in different forms such as; nanoparticles, nanorods, nanowires, nanoflower, nanobelt, nanocolumn, nanoboat etc. have been prepared by different chemical methods ${ }^{(5,6)}$. Co-precipitation is a very simple and novel synthesis procedure to prepare $\mathrm{ZnO}$ in the above forms and widely used by many scientists/researchers. These methods are also used for doping of different materials into semiconductor nanoparticles like $\mathrm{ZnO}$ to enhance its structural and optical properties. Impurity or dopants like rare earth elements are very crucial for enhancing the emission properties of $\mathrm{ZnO}$. The availability of $4 \mathrm{f}$ electrons which are involved in the spectroscopic transition leads to novel emissive properties when embedded in hosts like $\mathrm{ZnO}^{(7)}$. In the present work, we have doped Ce into $\mathrm{ZnO}$ to study its role in governing the structural/optical properties of $\mathrm{ZnO}$. Cerium can exist as $\mathrm{Ce}^{4+}$ or $\mathrm{Ce}^{3+}$ and have the greatest chance to modify the band structure of $\mathrm{ZnO}$.

\section{Materials and Method}

Precursor materials of Zinc and cerium ions such as, zinc acetate $\left(\mathrm{Zn}\left(\mathrm{CH}_{3} \mathrm{COO}\right)_{2} \cdot 2 \mathrm{H}_{2} \mathrm{O}\right)$ and cerium nitrate $\left(\mathrm{Ce}\left(\mathrm{NO}_{3}\right)_{3} \cdot 6 \mathrm{H}_{2} \mathrm{O}\right)$ of analytical grade were procured from M/s Sigma Aldrich and used for synthesizing $\mathrm{ZnO}$ and Ce doped $\mathrm{ZnO}$. These salts were dissolved in double distilled water and continuously stirred. A magnetic stirrer was used for this purpose. Liquid ammonia solution (25\%) was added to the above solution drop-wise to get precipitation. The $\mathrm{pH}$ of the solution was measured in the range of 8.5 to 10.5 before and after the process of precipitation. The precipitates were centrifuged and collected for washing with water and acetone. The samples were dried at $100^{\circ} \mathrm{C}$ overnight. In this process pristine $\mathrm{ZnO}$ and cerium doped $\mathrm{ZnO}$ were prepared. The chemical reactions taking place during the process can be enumerated as given below:

$$
\begin{aligned}
& \mathrm{NH}_{3}+\mathrm{H}_{2} \mathrm{O} \rightarrow \mathrm{NH}_{3} . \mathrm{H}_{2} \mathrm{O} \rightarrow \mathrm{NH}_{4}{ }^{+}+\mathrm{OH}^{-} \\
& \mathrm{Zn}\left(\mathrm{CH}_{3} \mathrm{COO}\right)_{2}{ }^{\circ} \mathrm{Zn}^{2+}+2 \mathrm{CH}_{3} \mathrm{COO}^{-} \\
& \mathrm{Zn}^{2+}+2 \mathrm{OH}-\rightarrow \mathrm{ZnO}+\mathrm{H}_{2} \mathrm{O} \\
& \mathrm{Ce}\left(\mathrm{NO}_{3}\right)_{3} \cdot 6 \mathrm{H}_{2} \mathrm{O} \rightarrow \mathrm{Ce}^{3+}+3 \mathrm{NO}_{3}{ }^{-}+6 \mathrm{H}_{2} \mathrm{O} \\
& \mathrm{Ce}^{3+}+4 \mathrm{OH}^{-} \rightarrow \mathrm{CeO}_{2}+2 \mathrm{H}_{2} \mathrm{O}+\mathrm{e}^{-} \\
& \mathrm{NO}_{3}{ }^{-}+\mathrm{H}_{2} \mathrm{O}+2 \mathrm{e}^{-} \rightarrow-\mathrm{NO}_{2}{ }^{-}+2 \mathrm{OH}^{-}
\end{aligned}
$$

The structural and phase studies were carried out by using a powder X-ray diffractometer (M/s Panalytical, X pert Pro). The surface morphology was studied by a FESEM (ZEISS Supra) and FTIR patterns were recorded by a Perkin-Elmer spectrometer. Room temperature photoluminescence measurement was taken by a Fluormax- 4 spectrometer made by M/s Perkin-Elmer.

\section{Results and Discussion}

\subsection{X-Ray Diffraction Studies}

XRD measurement gives useful information on the crystal structure and phase of the sample and has been carried out for all the samples. Pristine $\mathrm{ZnO}$ and $\mathrm{Ce}-\mathrm{ZnO}$ are of crystalline nature and show hexagonal wurtzite phase as studied from the XRD patterns depicted in Figure-1. There exist nine diffraction peaks which are indexed as (100), (002), (101), (102), (110), (103), (200), (112) and (201) ${ }^{(8)}$. Among these peaks, the (101) diffraction peak has highest intensity both for $\mathrm{ZnO}$ and Ce-doped $\mathrm{ZnO}$. Peaks corresponding to cerium are also detected in XRD pattern of Ce-ZnO. These are observed around 24, 26 and 41 degree along with some $\mathrm{Zn}(\mathrm{OH})_{2}$ phase. The particle size of the samples is calculated by the Scherrer formula given by $\mathrm{D}=\mathrm{kl} / \mathrm{bcosq}$. Here, the parameters like D is the size, 1 is the $\mathrm{x}$-ray wavelength (1.5406 $\AA$ ), $\mathrm{b}$ is the peak FWHM, $\mathrm{q}$ is the diffracting angle and $\mathrm{k}=0.94^{(8)}$. Lattice micro-strain is calculated using the formula; $\mathrm{e}=\mathrm{b} / 4$ tanq. With cerium doping, the value of crystallite size is found to be higher as compared to pristine $\mathrm{ZnO}$ (Table-1). The strain value also increases with doping along with unit cell volume. The data obtained from XRD measurement has been given in Table-1. $\mathrm{Ce}^{3+}$ ions may have substituted the $\mathrm{Zn}^{2+}$ ions in $\mathrm{ZnO}$ lattice leading to these results. The ionic radius of $\mathrm{Ce}^{3+}(1.03 \AA)$ is much higher than that of $\mathrm{Zn}^{2+}(0.74 \AA)^{(7)}$. This gives a clear picture about the influence of cerium doping on the structural properties of $\mathrm{ZnO}$. 
Table 1. Crystallographicparameters of $\mathrm{ZnO}$ and Ce doped $\mathrm{ZnO}$ obtained from XRD measurements

\begin{tabular}{|c|c|c|c|c|c|c|c|}
\hline \multirow[t]{2}{*}{ Sample } & \multirow[t]{2}{*}{ Size $(\mathrm{nm})$} & \multirow[t]{2}{*}{ Stain } & \multicolumn{3}{|c|}{ Lattice Parameter } & \multirow[t]{2}{*}{ Bond Length $(\AA ̊)$} & \multirow{2}{*}{$\begin{array}{l}\text { Unit cell volume } \\
(\AA)\end{array}$} \\
\hline & & & $\mathrm{a}(\AA)$ & $C(\AA)$ & $\mathrm{u}$ & & \\
\hline $\mathrm{ZnO}$ & 36 & 0.0030 & 3.249 & 5.209 & 0.379 & 1.9355 & 47.2457 \\
\hline $\mathrm{Ce}-\mathrm{ZnO}$ & 17 & 0.0064 & 3.240 & 5.210 & 0.378 & 1.9883 & 47.2677 \\
\hline
\end{tabular}

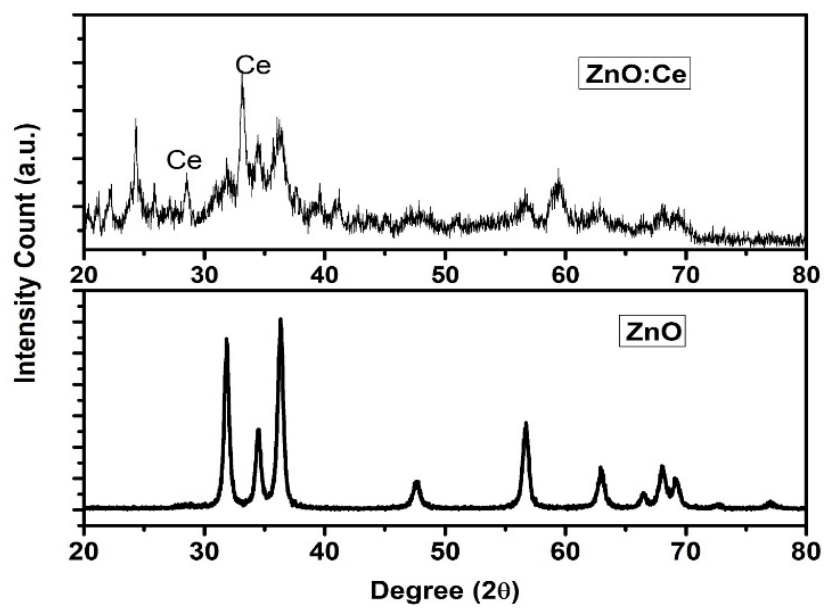

Fig 1. XRD patterns of $\mathrm{ZnO}$ and cerium doped $\mathrm{ZnO}$.

\subsection{FESEM Studies}

The shape and size of a material collectively gives the information on the morphology which has been studied by FESEM measurement. Surface property of nanomaterials is an essential parameter in influencing the optical emission processes. The images obtained for $\mathrm{Ce}-\mathrm{ZnO}$ have been shown in Figure-2. It shows the formation of flower-like structure of $\mathrm{ZnO}$ with $\mathrm{Ce}$ doping. The dopant incorporation in $\mathrm{ZnO}$ is also confirmed by EDAX measurement and given in the same figure.

\subsection{UV-VIS absorbance Studies}

The interaction of light in UV-VIS (300-700 $\mathrm{nm}$ ) range on the sample ( $\mathrm{ZnO}$ and Ce-ZnO) has been studied by recording the optical absorption spectrum. The nanopowders are made ready for measurement by dispersing them in acetone and filled in the quartz cuvette. Figure- 3 shows the absorbance spectra of $\mathrm{ZnO}$ and $\mathrm{Ce}-\mathrm{ZnO}$. Both the spectra show a clear peak in the region (360-370 nm) which is the absorption band of $\mathrm{ZnO}$. It is found at $362 \mathrm{~nm}$ for $\mathrm{ZnO}$ but shifts to $365 \mathrm{~nm}$ for Ce doped ZnO. This shift in the absorption peak may be due to cerium doping.

\subsection{FTIR Studies}

To understand the vibrational properties of $\mathrm{ZnO}$ before and after doping, the FTIR measurements are performed and illustrated in Figure-4. The existence of all the functional groups in a sample can be confirmed by the unique and characteristic absorption of IR radiation by the sample ${ }^{(9,10)}$. The IR light in the form of energy lets the bonds present in a molecule to bend and stretch that can be recorded in IR spectrum. The spectra recorded by us are in the range of $4000-400 \mathrm{~cm}^{-1}$. Both the spectrum for pristine and doped $\mathrm{ZnO}$ has shown many bands which has been assigned to different vibrations as given below.

Band around $3000-3600 \mathrm{~cm}^{-1}$ : ascribed to $-\mathrm{OH}$ groups ${ }^{(10)}$

Band around $1350 \mathrm{~cm}^{-1}$ : ascribed to $\mathrm{N}-\mathrm{O}$ stretching modes ${ }^{(10)}$

Band around $910 \mathrm{~cm}^{-1}$ : ascribed to stretching vibrations of $\mathrm{N}-\mathrm{H}$ groups ${ }^{(10)}$

Band around $600-400 \mathrm{~cm}^{-1}$ : ascribed to metal-oxygen vibrational modes ${ }^{(10)}$ 

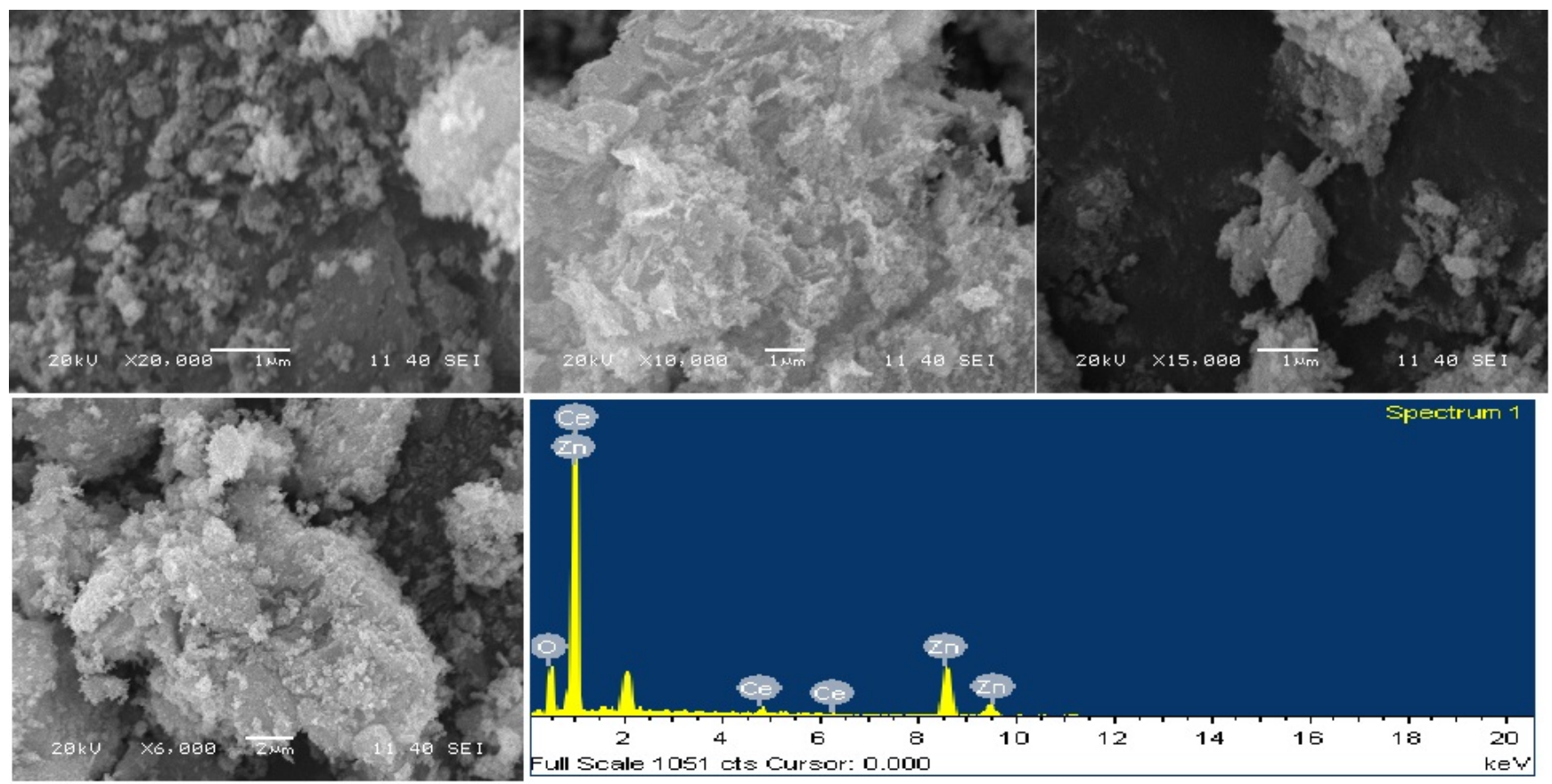

Fig 2. FESEM images and EDAX pattern of Cerium doped ZnO.

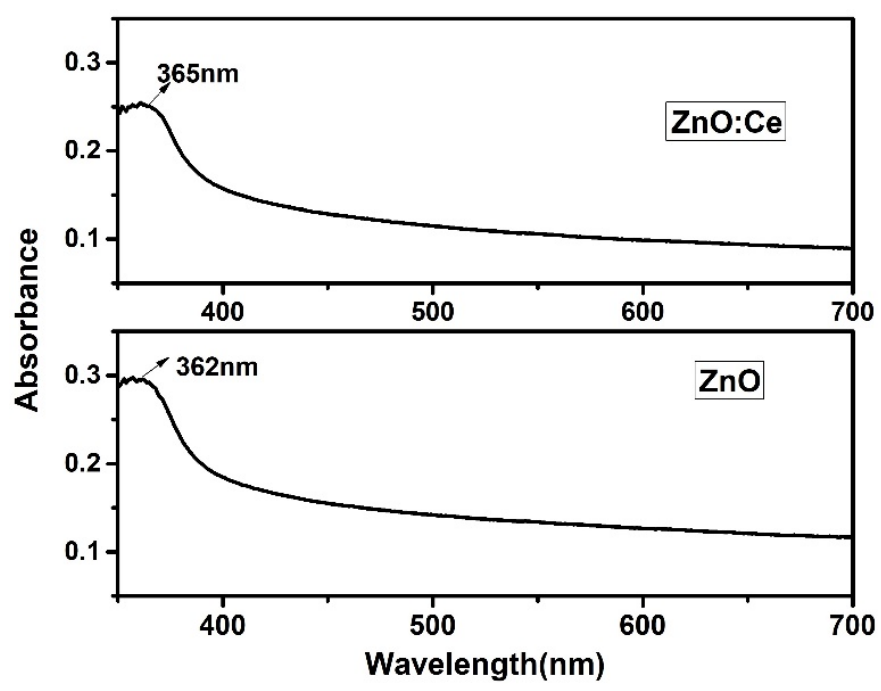

Fig 3. UV-Vis absorption spectra of $\mathrm{ZnO}$ and cerium doped $\mathrm{ZnO}$

\subsection{Photoluminescence Studies}

Photoluminescence measurements have been performed by exciting samples with light and recording the emission spectrum. These spectra for $\mathrm{ZnO}$ and $\mathrm{Ce}-\mathrm{ZnO}$ have been shown in Figure-5. The spectrum for $\mathrm{ZnO}$ shows the excitonic emission around $400 \mathrm{~nm}$ and defect emissions around 430, 460 and $570 \mathrm{~nm}$ with excitation of light of $350 \mathrm{~nm}^{(11-13)}$. The PL spectrum for Ce$\mathrm{ZnO}$ also shows the excitonic emission of $\mathrm{ZnO}^{(12,13)}$. It also shows two clear and sharp peaks around $520 \mathrm{~nm}$ and $640 \mathrm{~nm}$. The peak in the green region may be due to the presence of oxygen vacancies ${ }^{(13)}$. The red emission in Ce- $\mathrm{ZnO}$ is assigned to the transition related to the dopant. 


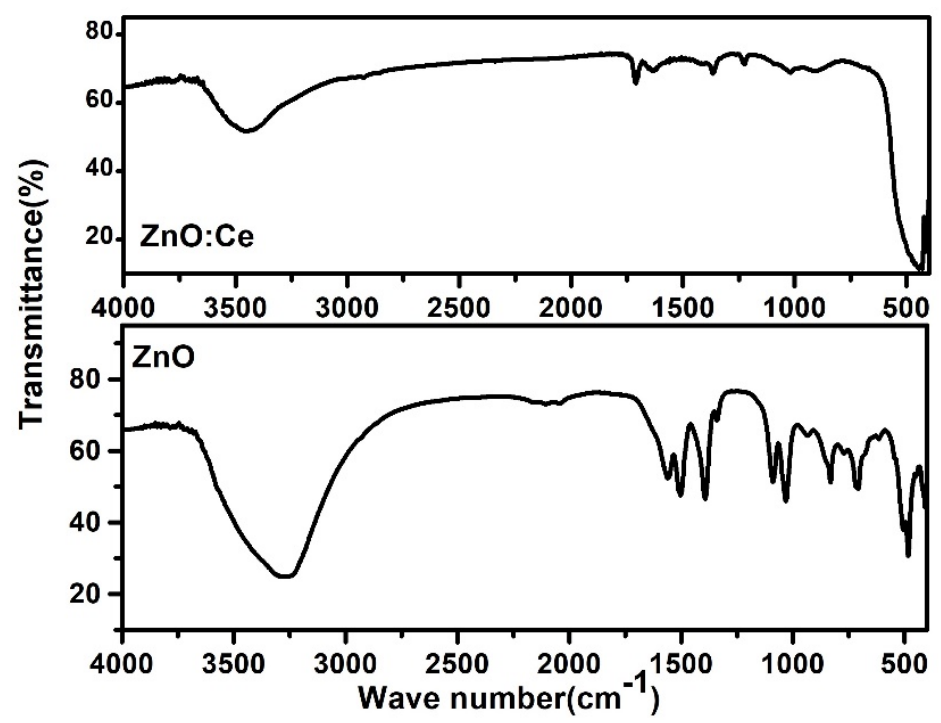

Fig 4. FTIR spectra of $\mathrm{ZnO}$ and Cerium doped $\mathrm{ZnO}$.

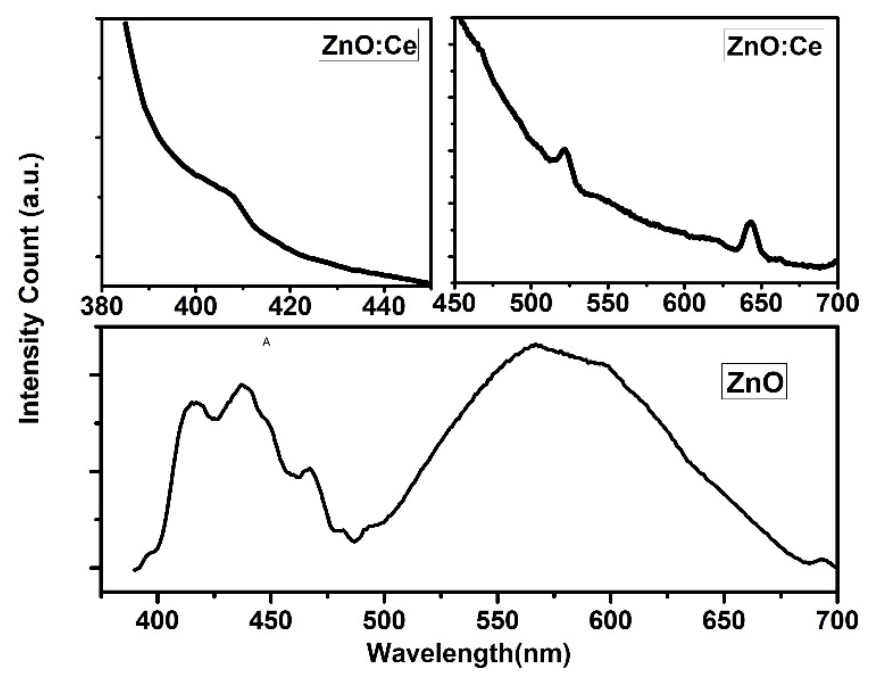

Fig 5. PL spectra of $\mathrm{ZnO}$ and Cerium doped $\mathrm{ZnO}$.

\section{Conclusion}

The present study deals with the synthesis of rare earth (Ce) ion doped $\mathrm{ZnO}$ nanopowder by chemical precipitation method. Study is also carried out to understand the structural and optical property of pristine and doped $\mathrm{ZnO}$. XRD measurements show the nanopowders have size in nano range and cerium doping increases the size, strain and unit cell volume of $\mathrm{ZnO}$. The FESEM measurement shows the morphology of the doped sample to be flower like. UV-VIS absorbance spectra confirm the absorption band of $\mathrm{ZnO}$ in the region around $360 \mathrm{~nm}$ which shifts with cerium doping. FTIR spectra depicts the existence of different stretching and bending vibration along with metal-oxygen bond in the sample. The Pl spectra show the excitonic emission along with defect emission of $\mathrm{ZnO}$. With cerium doping, emissions in the red region is observed.

\section{Acknowledgement}

Dr. Dojalisa Sahu is thankful to Prof. Supriya Pattanayak, Vice Chancellor, CUTM for constant encouragement to carry out this work. 


\section{References}

1) Sengupta A, Sarkar CK. Introduction to Nano: Basics to Nanoscience and Nanotechnology. Berlin. Springer-Verlag. 2015. doi:10.1007/978-3-662-47314-6.

2) Reynolds DC, Look DC, Jogai B. Optically pumped ultraviolet lasing from ZnO. Solid State Communications. 1996;99:873-875. doi:10.1016/00381098(96)00340-7.

3) Panda NR, Acharya BS, Nayak P. Growth and enhanced optical properties of ZnO:S nanorods and multipodes. Materials Letters. 2013;100:257-260. doi:10.1016/j.matlet.2013.03.059.

4) Klingshirn CF, Meyer BK, Waag A, Hoffmann A, J G. Zinc oxide-from fundamental properties towards novel application. vol. 120. Springer-Verlag. 2010. doi:10.1007/978-3-642-10577-7.

5) Elias J, Tena-Zaera R, Lévy-Clément C. Effect of the Chemical Nature of the Anions on the Electrodeposition of ZnO Nanowire Arrays. The Journal of Physical Chemistry C. 2008;112(15):5736-5741. doi:10.1021/jp7120092.

6) Zhang J, Sun, Yin, Su, Liao, Yan. Control of ZnO Morphology via a Simple Solution Route. Chemistry of Materials. 2002;14(10):4172-4177. doi:10.1021/cm020077h.

7) Panda NR, Acharya BS, Singh TB, Gartia RK. Luminescence properties and decay kinetics of nano ZnO powder doped with cerium ions. Journal of Luminescence. 2013;136:369-377. doi:10.1016/j.jlumin.2012.12.002.

8) Sahu D, Acharya BS, Panda AK. Role of Ag ions on the structural evolution of nano ZnO clusters synthesized through ultrasonication and their optical properties. Ultrasonics Sonochemistry. 2011;18:601-607. doi:10.1016/j.ultsonch.2010.08.012.

9) Kalsi PS, Organic SO, Compound. 2004. Available from: https://books.google.co.in/books?id=QWq47QClOM0C\&printsec=frontcover\&dq= Spectroscopy+of+Organic+Compounds.

10) Coates J. Interpretation of infrared spectra: a practical approach. In: Meyers RA, et al., editors. In: Encyclopedia of Analytical Chemistry. John Wiley \& Sons Ltd. 2000. doi:10.1002/9780470027318.a5606.

11) Sahu D, Acharya BS, Bag BP, Singh TB, Gartia RK. Probing the surface states in nano ZnO powder synthesized by sonication method: Photo and thermoluminescence studies. Journal of Luminescence. 2010;130(8):1371-1378. doi:10.1016/j.jlumin.2010.02.049.

12) Roychowdhury A, Pati SP, Mishra AK, Kumar S, Das D. Magnetically addressable fluorescent Fe3O4/ZnO nanocomposites: Structural, optical and magnetization studies. Journal of Physics and Chemistry of Solids. 2013;74(6):811-818. doi:10.1016/j.jpcs.2013.01.012.

13) Vanheusden K, Warren WL, Seager CH, Tallant DR, Voigt JA, Gnade BE. Mechanisms behind green photoluminescence in ZnO phosphor powders. Journal of Applied Physics. 1996;79(10):7983-7990. doi:10.1063/1.362349. 